\title{
Diagnostic accuracy of the aspartate aminotransferase-to-platelet ratio index for the prediction of hepatitis B-related fibrosis: a leading meta-analysis
}

Wenwen Jin ${ }^{1,3+}$, Zhonghua Lin ${ }^{1,3+}$, Yongning Xin ${ }^{1,2,3^{*}}$, Xiangjun Jiang ${ }^{1,3}$, Quanjiang Dong ${ }^{1,3}$ and Shiying Xuan ${ }^{1,2,3^{*}}$

\begin{abstract}
Background: The aspartate aminotransferase-to-platelet ratio index (APRI), a tool with limited expense and widespread availability, is a promising noninvasive alternative to liver biopsy for detecting hepatic fibrosis. The objective of this study was to systematically review the performance of the APRI in predicting significant fibrosis and cirrhosis in hepatitis B-related fibrosis.
\end{abstract}

Methods: Areas under summary receiver operating characteristic curves (AUROC), sensitivity and specificity were used to examine the accuracy of the APRI for the diagnosis of hepatitis B-related significant fibrosis and cirrhosis. Heterogeneity was explored using meta-regression.

Results: Nine studies were included in this meta-analysis $(n=1,798)$. Prevalence of significant fibrosis and cirrhosis were $53.1 \%$ and $13.5 \%$, respectively. The summary AUCs of the APRI for significant fibrosis and cirrhosis were 0.79 and 0.75 , respectively. For significant fibrosis, an APRI threshold of 0.5 was $84 \%$ sensitive and $41 \%$ specific. At the cutoff of 1.5 , the summary sensitivity and specificity were $49 \%$ and $84 \%$, respectively. For cirrhosis, an APRI threshold of 1.0-1.5 was 54\% sensitive and $78 \%$ specific. At the cutoff of 2.0, the summary sensitivity and specificity were $28 \%$ and $87 \%$, respectively. Meta-regression analysis indicated that the APRI accuracy for both significant fibrosis and cirrhosis was affected by histological classification systems, but not influenced by the interval between Biopsy \& APRI or blind biopsy.

Conclusion: Our meta-analysis suggests that APRI show limited value in identifying hepatitis B-related significant fibrosis and cirrhosis.

Keywords: APRI, HBV, liver fibrosis, diagnostic accuracy, meta-analysis

\section{Background}

Chronic hepatitis B virus (HBV), with which more than 400 million people are infected over the world, causes a worldwide health problem. It is the most common cause of acute and chronic liver disease worldwide, eventually progressing from fibrosis to cirrhosis and/or hepatocellular carcinoma [1]. It is well known that the exact staging of liver fibrosis is crucial for the therapeutic decision and assessing of the prognosis of CHB patients.

\footnotetext{
*Correspondence: xinyongning@163.com; dxyxyn@163.com + Contributed equally

'Qingdao Municipal Hospital, Qingdao 266021, Shandong Province, China Full list of author information is available at the end of the article
}

Currently, liver biopsy, the gold standard, is limited by invasiveness, complications, sampling error, variability in pathological interpretation, and the reluctance of patients to undergo repeated biopsies to monitor disease progression $[2,3]$, and $0.2-2 \%$ morbidity rate $[4,5]$. Because of these limitations, noninvasive measures have been examined by numerous studies to grade liver fibrosis. The aspartate aminotransferase-to-platelet ratio index (APRI) was first reported and used to identify patients with HCV-related hepatic fibrosis by Wai and his colleague in 2003 [6]. This index has the advantage of including only 2 inexpensive laboratory tests, which are performed routinely in all patients. The APRI has 
shown great value in predicting HCV-related fibrosis. So far, there have been several researches conducted to assess the APRI for predicting the fibrosis stage of HBV patients, and some of the existing researches are controversial. The objective of this study was to systematically review the diagnostic accuracy of the APRI for the prediction of significant fibrosis and cirrhosis in hepatitis B-related fibrosis.

\section{Methods}

\section{Search Strategy}

The objective of our search was to identify published manuscripts of studies examining the APRI for the prediction of HBV-related fibrosis. An electronic search, without language limitations, was completed on MEDLINE, EMBASE, and China National Knowledge Infrastructure (CNKI) including the following terms: APRI, AST, platelet, hepatitis B, AST-to-platelet ratio index, and fibrosis markers (01/2003-03/ 2011). Additional studies were identified via a manual search of the reference lists of relevant studies. Studies were selected if they met the following inclusion criteria:

(1) The study evaluated the performance of the APRI for the prediction of fibrosis in HBV-infected patients. Studies including patients with other causes of liver disease were included if data for HBV-infected patients could be extracted.

(2) Liver biopsy was used as the reference standard for assessing fibrosis. According to METAVIR or comparable systems, they classified the fibrosis stages $\mathrm{F} \geq 2, \mathrm{~F} \geq$ 4; the Ishak system was $\mathrm{F} \geq 3, \mathrm{~F} \geq 5$.

(3) In order to calculate the indexes (sensitivity, specificity, positive predictive value and negative predictive value) of each cut-off point, data could be extracted to allow the construction of at least one $2 \times 2$ table of test performance.

(4) The study included more than 40 patients. Smaller studies were excluded because of poor reliability.

\section{Data Abstraction}

Two reviewers (JIN and LIN) independently evaluated the study eligibility, graded quality, and extracted outcome data. Disagreements were resolved by consensus. To assess the methodological quality of the studies included in the meta-analysis, the Quality Assessment of Diagnostic Accuracy Studies score was used $[7,8]$.

The primary outcome was the identification of significant fibrosis, defined as METAVIR [9], Batts and Ludwig [10], or Scheuer [11] stages F2 through F4 or Ishak stages F3 through F6 [12]. We also examined the identification of cirrhosis (METAVIR, Batts and Ludwig, or Scheuer F4, or Ishak F5-6).

\section{Data Synthesis and Analysis}

For each test threshold and outcome, we tabulated the data in $2 \times 2$ tables to count the sensitivity and specificity. In view of previous study's primary thresholds of 0.5 and1.5 for significant fibrosis and 1.0-1.5 and 2.0 for cirrhosis, we examined the areas under summary receiver operating characteristic (SROC) curves, the summary sensitivities and specificities to provide the summary measures of test performance across all tests and these thresholds. We also calculated Q (which is defined by the point where sensitivity and specificity is equal, and is the best tool to reflect the diagnosis value)to assess the diagnostic accuracy and used Random effects meta-regression [13] to examine the impact of the following factors on identifying significant fibrosis: (a) interval between Biopsy \& APRI( $\leq 1$ week or other); (b) histopathological classification systems (METAVIR, or Scheuer, Ishak, Batts and Ludwig); (c) blind biopsy (yes vs. no). All the data were analyzed in the Meta-Disc software (version 1.4).

\section{Results}

Sixteen studies were identified that described the APRI in patients with chronic hepatitis B (Figure 1). Ultimately, 7 studies were excluded for insufficient data $(\mathrm{n}=4)$ [14-17], duplication of data $(\mathrm{n}=1)$ [18], small sample size or any other cause of chronic liver disease $(n=2)[19,20]$. Thus, our final data set for the metaanalysis included 9 studies (Table 1) [21-29].

\section{Characteristics of the Included Studies}

Table 1 shows the main features of our eligible studies. A total of 1,798 patients (median age, 34.6 years; $79.4 \%$ male) were included. The overall prevalence of significant fibrosis and cirrhosis were 53.1\% (range, $21.7 \%-83 \%$ ) and $13.5 \%$ (3.4\%-40.2\%), respectively. Regarding histological classification systems, 5 studies used METAVIR score, 2 used Scheuer score, 1 used Ishak score, and 1 used Batts and Ludwig score. According to the Quality Assessment of Diagnostic Accuracy Studies scale, we can see that seven studies met all 14 requirements of this scale, 1 study met 13 , and 1 study met 12 . The methodological quality of the included studies was very good.

According to the meta-regression, the APRI accuracies for detecting significant fibrosis and cirrhosis were not affected by the interval between Biopsy \& APRI ( $\mathrm{P}=$ $0.22, \mathrm{P}=0.42)$, or blind biopsy $(\mathrm{P}=0.09, \mathrm{P}=0.57)$, and were both influenced by histological classification systems $(\mathrm{P}=0.01, \mathrm{P}=0.03)$,

\section{Diagnostic Accuracy of the APRI for the Prediction of Significant Fibrosis}

Seven studies in 1,404 patients assessed the APRI for the prediction of significant fibrosis. The average prevalence of significant fibrosis in these studies was $53.1 \%$ (range, 
Total numbers of papers retrieved on search $(n=28)$

\section{Studies Excluded \\ Reviews and only abstract $(\mathrm{n}=7)$ \\ Relevant to treatment $(n=2)$}

Potentially relevant studies identified
for evaluation $(n=19)$

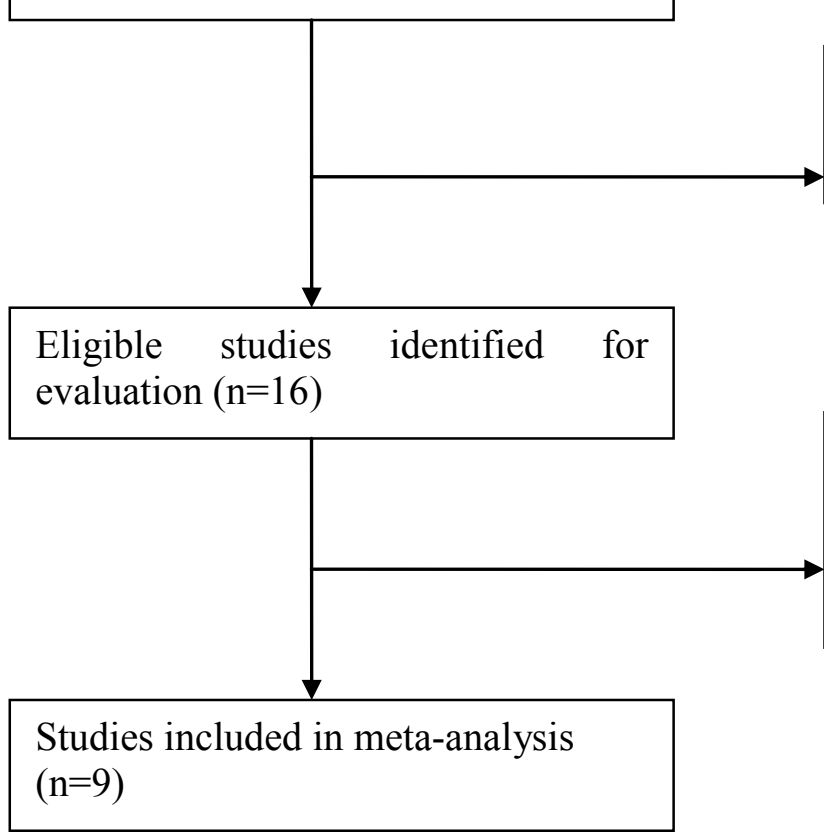

Figure 1 Flow chart of article selection.

$21.7 \%-83 \%)$. For this outcome, the area under the SROC curve was $0.79(\mathrm{SE}=0.0243)$ and the $\mathrm{Q}$ index was 0.72 $(\mathrm{SE}=0.0208)$ (Figure 2). The summary sensitivities and specificities of the APRI at various thresholds for the identification of significant fibrosis were listed in Table 2. At the threshold of 0.5 , the summary sensitivity and specificity were $84 \%$ (95\% CI, $81 \%-88 \%$ ) and $41 \%$ (36\%-46\%), respectively. At the cutoff of 1.5 , the summary sensitivity and specificity were $49 \%$ (95\% CI, 44\%-53\%) and $84 \%$ (80\%-88\%), respectively. Based on these data, and assuming a $53.1 \%$ prevalence of significant fibrosis (as observed in the included studies), the estimated PPV and NPV of 0.5 were $64 \%$ and $68 \%$. At the 1.5 cutoff, the estimated PPV and NPV were $80 \%$ and $57 \%$, respectively.

\section{Diagnostic Accuracy of the APRI for the Prediction of} Cirrhosis

Six studies in 1,012 patients assessed the APRI for the prediction of cirrhosis. The average prevalence of cirrhosis in these studies was 13.5\% (range, 3.4\%-40.2\%). For this outcome, the area under the SROC curve was $0.75(\mathrm{SE}=0.0237)$ and the $\mathrm{Q}$ index was $0.70(\mathrm{SE}=$ 0.0197 ) (Figure 3). At the threshold of 1.0-1.5, the summary sensitivity and specificity were 54\% (95\% CI, 48\%$60 \%)$ and $78 \%$ (75\%-80\%), respectively. At the cutoff of 2.0 , the summary sensitivity and specificity were $28 \%$ (95\% CI, 21\%-35\%) and 87\% (84\%-89\%), respectively. Based on these data, and assuming a $13.5 \%$ prevalence of cirrhosis (as observed in the included studies), the estimated PPV and NPV of $1.0-1.5$ were $39 \%$ and $86 \%$, respectively. At the 2.0 cutoff, the estimated PPV and NPV were $36 \%$ and $82 \%$, respectively.

Figures 4 and 5 show the funnel plot analysis to detect the publication bias of each study for significant fibrosis and cirrhosis, respectively. The shape of the funnel plot seems to be asymmetrical, suggesting that publication bias might affect the findings of our meta-analysis. 
Table 1 Characteristics of the Included Studies

\begin{tabular}{|c|c|c|c|c|c|c|c|c|}
\hline $\begin{array}{l}\text { Author, Year, } \\
\text { Country }\end{array}$ & $\begin{array}{c}\text { Study/ } \\
\text { center } \\
\text { Description }\end{array}$ & $N$ & $\begin{array}{c}\text { Interval } \\
\text { Between } \\
\text { Biopsy \& APRI }\end{array}$ & $\begin{array}{l}\text { Median/Mean } \\
\text { Age, (\% male) }\end{array}$ & Etiology & $\begin{array}{c}\text { Liver } \\
\text { Biopsy } \\
\text { Description }\end{array}$ & $\begin{array}{c}\text { Prevalence } \\
\text { Significant } \\
\text { Fibrosis } \\
\text { (Cirrhosis) } \\
\end{array}$ & $\begin{array}{l}\text { QUADAS } \\
\text { Score }\end{array}$ \\
\hline $\begin{array}{c}\text { Chrysanthosa,2006, } \\
\text { Greece [31] }\end{array}$ & $\begin{array}{l}\text { Retrospective } \\
2 \text { centers }\end{array}$ & 205 & same day & $51 \pm 13(74.6 \%)$ & HBV & $\geq 1.5 \mathrm{~cm}$ & $42.33 \%(23.11 \%)$ & 14 \\
\hline $\begin{array}{l}\text { Liu Hongbo,2007, } \\
\text { China [33] }\end{array}$ & $\begin{array}{l}\text { Retrospective } \\
5 \text { centers }\end{array}$ & 444 & $\leq 1$ week & $\begin{array}{c}\text { Training group30(71\%) } \\
\text { Validation group28 } \\
\text { (79\%) }\end{array}$ & HBV & $\geq 1.0 \mathrm{~cm}$ & $30.18 \%(4.50 \%)$ & 14 \\
\hline $\begin{array}{l}\text { Giada Sebastiani, } \\
\text { 2007, Italy [10] }\end{array}$ & $\begin{array}{l}\text { Retrospective } \\
2 \text { centers }\end{array}$ & 110 & same day & $42.6 \pm 11.3(72.7 \%)$ & HBV & $\geq 1.5 \mathrm{~cm}$ & $68.20 \%(20 \%)$ & 14 \\
\hline $\begin{array}{c}\text { Beom Kyung Kim } \\
\text { 2007, Korea [35] }\end{array}$ & $\begin{array}{c}\text { Retrospective } \\
6 \text { centers }\end{array}$ & 346 & same time & $34 \pm 14(85.3 \%)$ & HBV & $4 \mathrm{~mm}$ & $75.4 \%(22.8 \%)$ & 14 \\
\hline $\begin{array}{l}\text { W.G. Shin,2008, } \\
\text { Korea [32] }\end{array}$ & $\begin{array}{l}\text { Retrospective } \\
2 \text { centers }\end{array}$ & 264 & same time & $24(87.1 \%)$ & HBV & $17 \mathrm{~mm}$ & $53.4 \%(3.4 \%)$ & 14 \\
\hline $\begin{array}{l}\text { ChenSheng, Lin } \\
\text { 2008, China [34] }\end{array}$ & $\begin{array}{c}\text { Retrospective } \\
3 \text { centers }\end{array}$ & 48 & Unclear & $60.4 \pm 11.3(74.2 \%)$ & HBV & Unclear & $21.70 \%(40.20 \%)$ & 12 \\
\hline $\begin{array}{l}\text { Ruidan Zheng, } \\
\text { 2008, China [36] }\end{array}$ & $\begin{array}{c}\text { Retrospective } \\
3 \text { centers }\end{array}$ & 131 & $\leq 1$ week & $34(84.333 \%)$ & HBV & $\geq 1.0 \mathrm{~cm}$ & $\begin{array}{l}55.126 \% \\
(8.897 \%)\end{array}$ & 14 \\
\hline $\begin{array}{l}\text { Zhongsheng jiang } \\
\text { 2008, China [37] }\end{array}$ & $\begin{array}{c}\text { Retrospective } \\
1 \text { center }\end{array}$ & 172 & $\leq 1$ day & $35(77.3 \%)$ & HBV & $\geq 1.5 \mathrm{~cm}$ & $83 \%(15 \%)$ & 14 \\
\hline $\begin{array}{l}\text { Sheng-Di Wu, } \\
\text { 2010, China [7] }\end{array}$ & $\begin{array}{c}\text { Retrospective } \\
1 \text { center }\end{array}$ & 78 & Unclear & $\begin{array}{c}32.6 \pm 12.3 \\
(84.6 \%)\end{array}$ & HBV & $\geq 15 \mathrm{~mm}$ & $41 \%(11.5 \%)$ & 13 \\
\hline
\end{tabular}

\section{Discussion}

Recently, the combination of FibroTest with FibroScan has demonstrated high diagnostic accuracy for the detection of significant fibrosis and cirrhosis [30]. However, the combination requires a complex instrument and is costly. Instead, the APRI is based on routinely performed, inexpensive laboratory parameters; it is potentially the ideal tool. The APRI has been derived and validated in HCV. In Wai and colleagues' original study [6], the AUC for HCV-related significant fibrosis and cirrhosis in the training and validation cohorts were 0.80 to 0.88 and 0.89 to 0.94 , respectively. Subsequently,

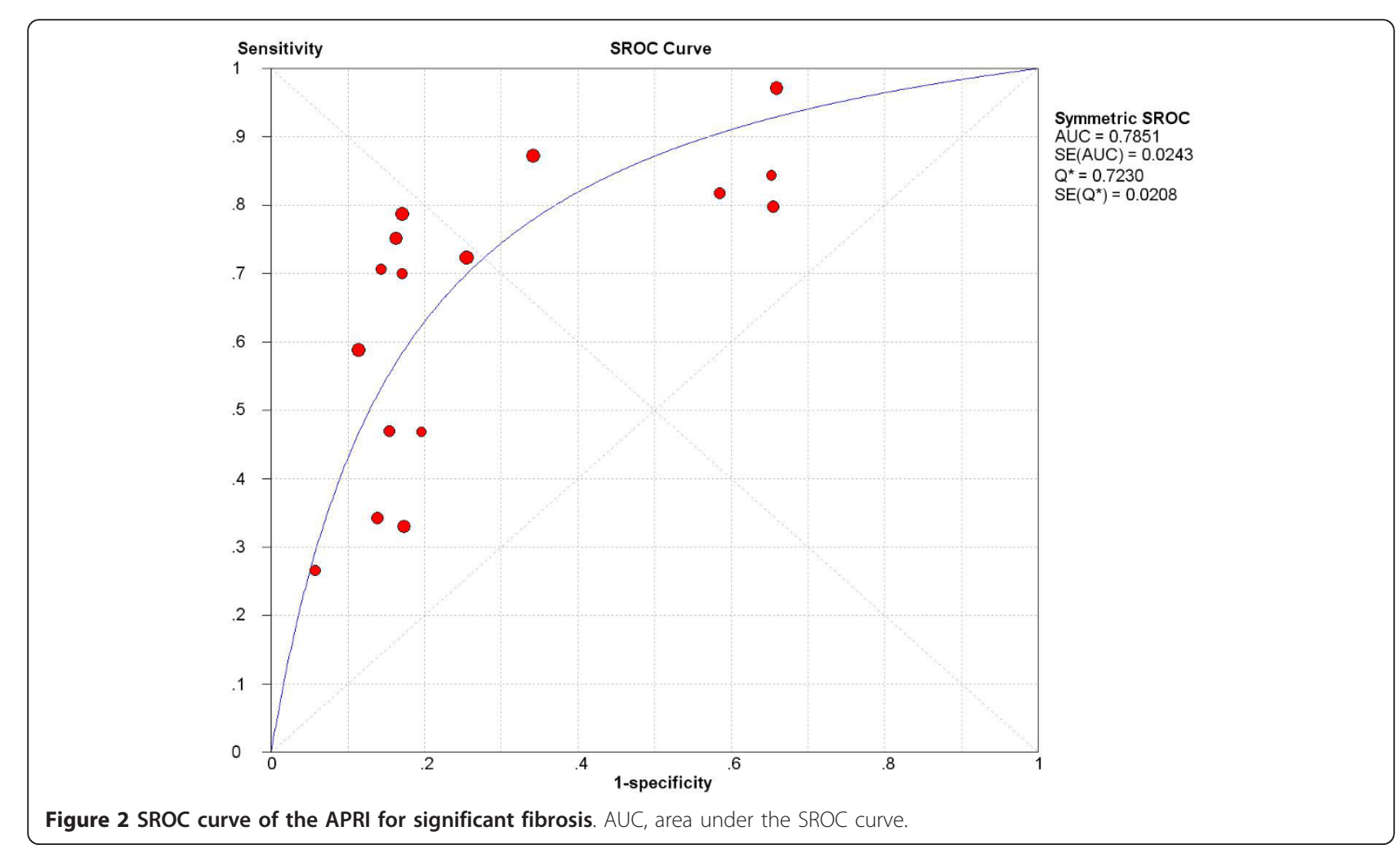


Table 2 Summary Sensitivities and Specificities of the APRI at various Diagnostic Thresholds for Prediction of Significant Fibrosis and Cirrhosis

\begin{tabular}{cccc}
\hline Test Threshold and Outcome & $\begin{array}{c}\text { Number of Studies } \\
\text { (Patients) }\end{array}$ & $\begin{array}{c}\text { Summary Sensitivity } \\
\mathbf{( 9 5 \% ~ C l )}\end{array}$ & $\begin{array}{c}\text { Summary Specificity } \\
\mathbf{( 9 5 \% ~ C l )}\end{array}$ \\
\hline Significant Fibrosis & & & $41 \%(36 \%-46 \%)$ \\
0.5 & $5(788)$ & $84 \%(81 \%-88 \%)$ & $84 \%(80 \%-88 \%)$ \\
1.5 & $5(788)$ & $49 \%(44 \%-53 \%)$ & $78 \%(75 \%-80 \%)$ \\
Cirrhosis & & & $87 \%(84 \%-89 \%)$ \\
$1-1.5$ & $6(1248)$ & $54 \%(48 \%-60 \%)$ & $28 \%(21 \%-35 \%)$ \\
\hline
\end{tabular}

many researches supported this view [31-35]. A meta analysis researched by Abdel Aziz $\mathrm{M}$ et al. pointed out, in patients with chronic viral hepatitis $\mathrm{C}(\mathrm{CHC})$, the summary AUCs of the APRI for significant fibrosis and cirrhosis were 0.76 [95\% CI: 0.74-0.79] and 0.82 [95\%CI: 0.79-0.86], respectively; an APRI threshold of 0.5 was $81 \%$ sensitive and $50 \%$ specific, at a $40 \%$ prevalence of significant fibrosis, this threshold had a negative predictive value (NPV) of $80 \%$. For cirrhosis, a threshold of 1.0 was $76 \%$ sensitive and $71 \%$ specific, at a $15 \%$ cirrhosis prevalence, the NPV of this threshold was 91\%, the major strength of the APRI is the exclusion of significant HCV-related fibrosis [36].

In contrast to $\mathrm{HCV}$, Wai et al. [14] evaluated the accuracy of models (ALT, AST and APRI) from HCV in 218 HBV patients, which indicated that non-invasive markers in predicting histology from $\mathrm{CHC}$ patients were unsuitable for $\mathrm{CHB}$ patients. Subsequent research demonstrated that in contrast to APRI, ASPRI was accurate in predicting cirrhosis and has the potential to reduce the number of liver biopsies in $\mathrm{CHB}$ patients when screening with ASPRI [27]. However, W.G. Shin and colleagues' study indicated that of indirect markers, the APRI yielded the best area (0.86) under the receiver operating characteristic curve [95\% CI: 0.82-0.91], the APRI may be the most accurate and simple marker for predicting significant fibrosis in chronic hepatitis B [24]. Lin CS and colleagues' research supported this view [26]. Thus, the present study conclusions are controversial. In our systematic review, we summarize the diagnostic accuracy of the APRI for the prediction of HBV-related fibrosis. In our systematic review, we calculated summary sensitivities

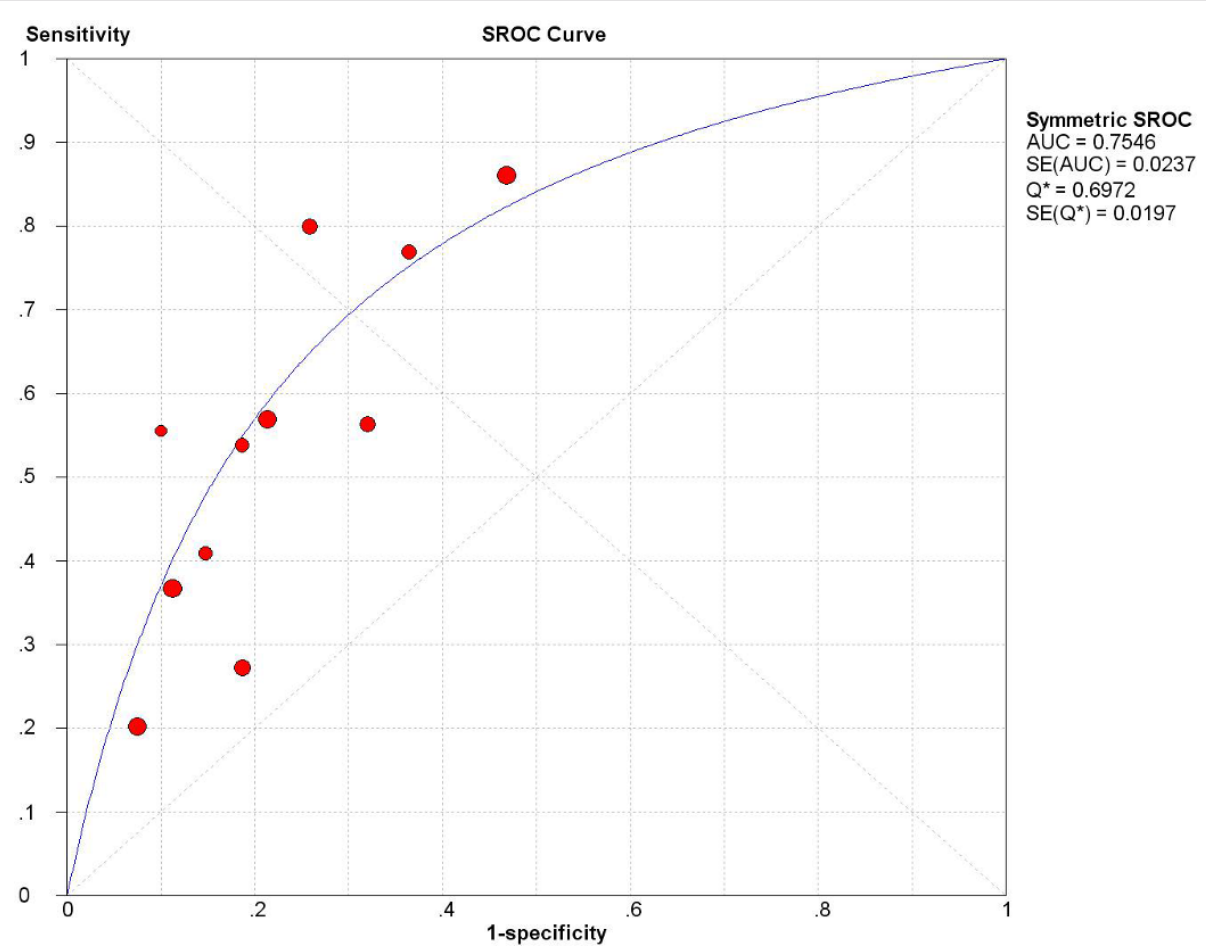

Figure 3 SROC curve of the APRI for cirrhosis. AUC, area under the SROC curve. 


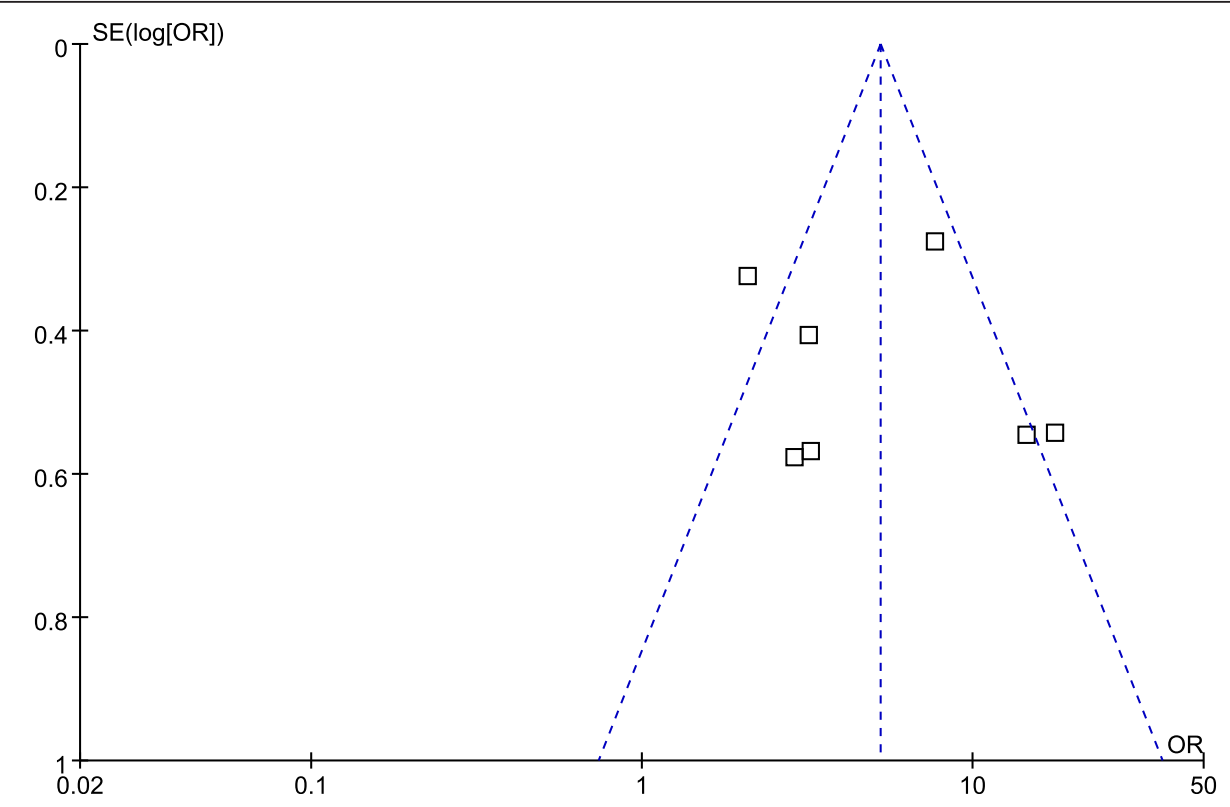

Figure 4 Funnel plot of APRI in significant fibrosis to explore publication bias.

and specificities at various thresholds to translate all point estimates into clinical practice. The summary AUROC of the APRI for the diagnosis of significant fibrosis was 0.79 . Moreover, the 0.5 threshold was $84 \%$ sensitive and $41 \%$ specific. Assuming a $53.1 \%$ prevalence of significant fibrosis, this translates into estimated PPV and NPV of $64 \%$ and $68 \%$, respectively. On the contrary, a cutoff of 1.5 was less sensitive (49\%) and more specific (84\%). Assuming a $53.1 \%$ prevalence of significant fibrosis, this translates into estimated $80 \% \mathrm{PPV}$ and $57 \%$ NPV. With regard to cirrhosis, the summary AUROC was 0.75 . Moreover, the1.0-1.5 threshold was $54 \%$ sensitive and $78 \%$ specific. Assuming a $13.5 \%$ prevalence of cirrhosis, this translates into estimated PPV and NPV of $39 \%$ and $86 \%$, respectively. On the contrary, a cutoff of 2.0 was less sensitive (28\%) and nearly specific (87\%). Assuming a $13.5 \%$ prevalence of cirrhosis, this translates into estimated 36\% PPV and 82\% NPV. A diagnostic tool

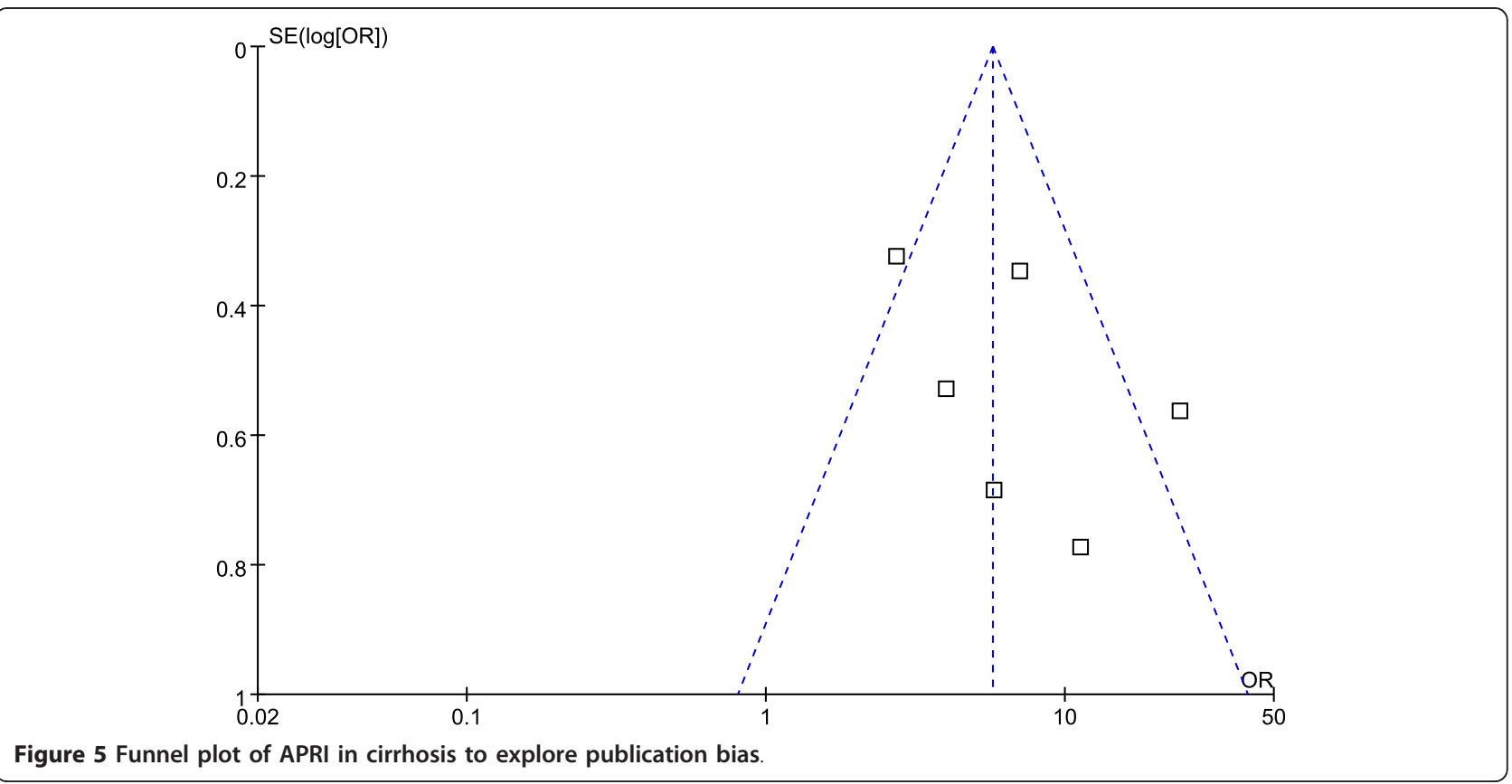


is considered as good if the AUROC is greater than $80 \%$, excellent if the AUROC is greater than $90 \%$ and perfect if the AUROC is $100 \%$. According to these results, the APRI may not be a good tool for predicting significant fibrosis and cirrhosis in hepatitis B-related fibrosis and can not reduce the number of liver biopsy.

A strength of our review is that meta-regression analyses have been used for exploring factors that may be responsible for heterogeneity. We analyzed carefully three indicators that might contribute to heterogeneity: (a) the interval between Biopsy \& APRI ( $\leq 1$ week or other); (b) blind biopsy (yes VS. no); (c) histological classification systems (METAVIR, Scheuer, Ishak, Batts and Ludwig). By meta-regression, we could see that for both significant fibrosis and cirrhosis, histological classification systems were found to provide heterogeneity to summary test results. Previous research has shown that the hypothesis of the liver biopsy is $80 \%-90 \%$ accurate, the AUC of medical tests cannot reach 0.9 , and more likely fluctuated from 0.75 to 0.9 [37]. To solve the problem, one of the ways is improving the quality of liver biopsies.

Our study has several limitations. Firstly, only HBVinfected patients have been analyzed. Losing some patients with mix infections (HBV/HCV, HBV/HIV and HBV/NAFLD) suggest reduced accuracy. Secondly, some of the studies reported APRI thresholds not included in the original description (Table 2). For example, W.G.Shin et al. proposed that the 1.4 cutoff appears promising (79\% sensitive; $83 \%$ specific for significant fibrosis) [24]. The number of studies is so small that we have not focused on these thresholds. Finally, we have chosen inclusions only by published manuscripts, so bias in the selection of search channels may influence the results to some extent.

In summary, our systematic review suggests that APRI show limited value in identifying hepatitis B-related significant fibrosis and cirrhosis. The APRI is not an appropriate choice for HBV patients to identify hepatitis B-related fibrosis in regions with limited health care resources. Future studies are necessary to identify high accuracy, cost-effectiveness and widely available measures.

\section{Conclusion}

Our meta-analysis suggests that APRI show limited value in identifying hepatitis B-related significant fibrosis and cirrhosis.

\section{Acknowledgements}

This work was partially supported by grants from the Natural Science Foundation of Shandong Province, China (No. ZR2009CQ031)

\footnotetext{
Author details

'Qingdao Municipal Hospital, Qingdao 266021, Shandong Province, China. ${ }^{2}$ College of Medicine and Pharmaceutics, Ocean University of China,
}

Qingdao 266003, Shandong Province, China. ${ }^{3}$ Qingdao City Key Laboratory of Digestive Diseases, Qingdao 266021, China.

\section{Authors' contributions}

WWJ and ZHL carried out the design of this meta-analysis, conducted the searching, extracted data, analyzed the data and drafted the manuscript. YNX and SYX participated in study design and the critical revision of the manuscript. XJJ and QJD participated in the critical revision of the manuscript. All authors read and approved the final manuscript.

\section{Competing interests}

The authors declare that they have no competing interests.

Received: 14 August 2011 Accepted: 14 February 2012

Published: 14 February 2012

\section{References}

1. Wright TL: Introduction to chronic hepatitis B infection. Am J Gastroenterol 2006, 101(Suppl 1):S1-6.

2. Friedman LS: Controversies in liver biopsy: who, where, when, how, why? Curr Gastroenterol Rep 2004, 6:30-36.

3. Bedossa $P$, Dargere $D$, Paradis V: Sampling variability of liver fibrosis in chronic hepatitis C. Hepatology 2003, 38:1449-1457.

4. Douds AC, Joseph AE, Finlayson C, et al: Is day case liver biopsy underutilised? Gut 1995, 37:574-575.

5. Piccinino F, Sagnelli E, Pasquale G, et al: Complications following percutaneous liver biopsy. A multicentre retrospective study on 68,276 biopsies. J Hepatol 1986, 2:165-173.

6. Wai $C T$, Greenson JK, Fontana RJ, et al: A simple noninvasive index can predict both significant fibrosis and cirrhosis in patients with chronic hepatitis C. Hepatology 2003, 38:518-526.

7. Whiting P, Rutjes AW, Reitsma JB, et al: The development of QUADAS: a tool for the quality assessment of studies of diagnostic accuracy included in systematic reviews. BMC Med Res Methodol 2003, 3:25.

8. Whiting P, Rutjes AW, Dinnes J, et al: Development and validation of methods for assessing the quality of diagnostic accuracy studies. Health Technol Assess 2004, 8:1-234, iii.

9. Bedossa P, Poynard T: An algorithm for the grading of activity in chronic hepatitis C. The METAVIR Cooperative Study Group. Hepatology 1996, 24:289-293.

10. Batts KP, Ludwig J: Chronic hepatitis. An update on terminology and reporting. Am J Surg Pathol 1995, 19:1409-1417.

11. Scheuer PJ: Classification of chronic viral hepatitis: a need for reassessment. J Hepatol 1991, 13:372-374.

12. Ishak K, Baptista A, Bianchi L, et al: Histological grading and staging of chronic hepatitis. J Hepatol 1995, 22:696-699.

13. Schmid CH, Stark PC, Berlin JA, et al: Meta-regression detected associations between heterogeneous treatment effects and study-level, but not patient-level, factors. J Clin Epidemiol 2004, 57:683-697.

14. Wai $C T$, Cheng $C L$, Wee $A$, et al: Non-invasive models for predicting histology in patients with chronic hepatitis B. Liver Int 2006, 26:666-672.

15. Xu J, Shi J, Wang YP, et al: Milder liver cirrhosis and loss of serum HBeAg do not imply lower risk for hepatocellular carcinoma development in HBV-related cirrhosis. Med Sci Monit 2009, 15:CR274-279.

16. Kim do Y, Kim SU, Ahn SH, et al: Usefulness of FibroScan for detection of early compensated liver cirrhosis in chronic hepatitis B. Dig Dis Sci 2009, 54:1758-1763.

17. Tu XL, Xiao YQ, Chen F: A noninvasive model to predict histological liver cirrhosis in patients with chronic hepatitis B. Zhonghua Gan Zang Bing Za Zhi 2009, 17:28-32

18. Zhang YX, Wu WJ, Zhang YZ, et al: Noninvasive assessment of liver fibrosis with combined serum aminotransferase/platelet ratio index and hyaluronic acid in patients with chronic hepatitis B. World J Gastroenterol 2008, 14:7117-7121.

19. Pissaia A Jr, Borderie D, Bernard D, et al: APRI and FIB-4 Scores Are Useful After Liver Transplantation Independently of Etiology. Transplant Proc 2009, 41:679-681.

20. Obara N, Ueno $Y$, Fukushima $K$, et al: Transient elastography for measurement of liver stiffness measurement can detect early significant hepatic fibrosis in Japanese patients with viral and nonviral liver diseases. J Gastroenterol 2008, 43:720-728. 
21. Wu SD, Wang JY, Li L: Staging of liver fibrosis in chronic hepatitis B patients with a composite predictive model: a comparative study. World J Gastroenterol 2010, 16:501-507.

22. Sebastiani $G$, Vario $A$, Guido $M$, et al: Sequential algorithms combining non-invasive markers and biopsy for the assessment of liver fibrosis in chronic hepatitis B. World J Gastroenterol 2007, 13:525-531.

23. Chrysanthos NV, Papatheodoridis GV, Savvas S, et al: Aspartate aminotransferase to platelet ratio index for fibrosis evaluation in chronic viral hepatitis. Eur J Gastroenterol Hepatol 2006, 18:389-396.

24. Shin WG, Park SH, Jang MK, et al: Aspartate aminotransferase to platelet ratio index (APRI) can predict liver fibrosis in chronic hepatitis B. Dig Liver Dis 2008, 40:267-274.

25. Hongbo L, Xiaohui L, Hong $K$, et al: Assessing routine and serum markers of liver fibrosis in CHB patients using parallel and serial interpretation. Clin Biochem 2007, 40:562-566.

26. Lin CS, Chang CS, Yang SS, et al: Retrospective evaluation of serum markers APRI and AST/ALT for assessing liver fibrosis and cirrhosis in chronic hepatitis B and C patients with hepatocellular carcinoma. Intern Med 2008, 47:569-575.

27. Kim BK, Kim SA, Park YN, et al: Noninvasive models to predict liver cirrhosis in patients with chronic hepatitis B. Liver Int 2007, 27:969-976.

28. Zheng RD ZK, Xian JC, Xu HT, Chen XX, Shen YL, Mao YM, Zeng MD, Lu LG: Assessment of noninvasive diagnostic models for predicting liver fibrosis in patients with chronic hepatitis B virus infection. Chin Hepatol 2008, 13:451-455.

29. Jiang ZS WX, Ke L, Tan C, Chen N, Li MJ: The diagnostic value of APRI and Forns index for liver fibrosis of chronic hepatitis B. Chin J Clini Hepatol 2008, 24:423-425.

30. Castera L, Vergniol J, Foucher J, et al: Prospective comparison of transient elastography, Fibrotest, APRI, and liver biopsy for the assessment of fibrosis in chronic hepatitis C. Gastroenterology 2005, 128:343-350.

31. Carvalho-Filho RJ, Schiavon LL, Narciso-Schiavon JL, et al: Optimized cutoffs improve performance of the aspartate aminotransferase to platelet ratio index for predicting significant liver fibrosis in human immunodeficiency virus/hepatitis C virus co-infection. Liver Int 2008, 28:486-493.

32. Sinn DH, Paik SW, Kang P, et al: Disease progression and the risk factor analysis for chronic hepatitis C. Liver Int 2008, 28:1363-1369.

33. Toniutto $P$, Fabris $C$, Bitetto $D$, et al: Role of AST to platelet ratio index in the detection of liver fibrosis in patients with recurrent hepatitis $C$ after liver transplantation. J Gastroenterol Hepatol 2007, 22:1904-1908.

34. Snyder N, Gajula L, Xiao SY, et al: APRI: an easy and validated predictor of hepatic fibrosis in chronic hepatitis C. J Clin Gastroenterol 2006, 40:535-542.

35. Fabris C, Smirne C, Toniutto P, et al: Assessment of liver fibrosis progression in patients with chronic hepatitis $\mathrm{C}$ and normal alanine aminotransferase values: the role of AST to the platelet ratio index. Clin Biochem 2006, 39:339-343.

36. Shaheen AA, Myers RP: Diagnostic accuracy of the aspartate aminotransferase-to-platelet ratio index for the prediction of hepatitis Crelated fibrosis: a systematic review. Hepatology 2007, 46:912-921.

37. Afdhal NH, Curry M: Technology evaluation: a critical step in the clinical utilization of novel diagnostic tests for liver fibrosis. J Hepatol 2007, 46:543-545.

\section{Pre-publication history}

The pre-publication history for this paper can be accessed here: http://www.biomedcentral.com/1471-230X/12/14/prepub

doi:10.1186/1471-230X-12-14

Cite this article as: Jin et al:: Diagnostic accuracy of the aspartate aminotransferase-to-platelet ratio index for the prediction of hepatitis B-related fibrosis: a leading meta-analysis. BMC Gastroenterology 2012 12:14.

\section{Submit your next manuscript to BioMed Central and take full advantage of:}

- Convenient online submission

- Thorough peer review

- No space constraints or color figure charges

- Immediate publication on acceptance

- Inclusion in PubMed, CAS, Scopus and Google Scholar

- Research which is freely available for redistribution

Submit your manuscript at www.biomedcentral.com/submit
Biomed Central 